\title{
Quality of life seems to be independent of severity of pretransplant illness in lung transplant recipients
}

\author{
Usman Ahmad, MD, and Kenneth R. McCurry, MD
}

From the Department of Cardiothoracic Surgery, Heart and Vascular Institute, Cleveland Clinic, Cleveland, Ohio. Disclosures: Authors have nothing to disclose with regard to commercial support.

Received for publication March 16, 2018; accepted for publication March 20, 2018; available ahead of print April 13, 2018.

Address for reprints: Usman Ahmad, MD, Department of Cardiothoracic Surgery, Heart and Vascular Institute, Cleveland Clinic, 9500 Euclid Ave, Cleveland, OH 44195 (E-mail: ahmadu@ccf.org).

J Thorac Cardiovasc Surg 2018;156:438-9

$0022-5223 / \$ 36.00$

Copyright (C) 2018 by The American Association for Thoracic Surgery

https://doi.org/10.1016/j.jtcvs.2018.03.065

The ultimate goal of any medical treatment is to achieve the best quantity of life while maintaining the best possible quality of life. One aspect alone does not do much good without the other. Lung transplantation is the ultimate palliative measure in patients with end-stage pulmonary disease. In patients with obstructive pulmonary disease, a transplant can improve quality of life. In the subsets of patients with pulmonary fibrosis and patients with pulmonary hypertension, the procedure also leads to survival advantage.

Patients on the verge of needing a lung transplant are the some of the sickest patients we deal with in our specialty. Air hunger is a powerful feeling, and it can make one extremely debilitated and afraid to ambulate or even exercise in bed. If you ask a patient in this condition if he or she is willing to undergo a high-stakes, high-reward operation that carries the potential of living an active life again, there is hardly anyone who would refuse a transplant. In this situation, the responsibility of selecting the right candidates, those who can be expected to benefit in terms of reasonable quality and quantity of life, falls on the treating physicians and surgeons.

In this issue of the Journal, Kolaitis and colleagues ${ }^{2}$ have tried to address the important question of which patients will benefit appropriately from a lung transplant. They have assessed and reported various measures of physical and mental quality of health in patients with or without preoperative extracorporeal membrane oxygenation (ECMO) support who received lung transplants. Their goal was to see whether pretransplant ECMO support attenuates the improvement in quality of life achieved with lung transplant. Not unexpectedly, regardless of pretransplant status (ECMO vs no ECMO), the quality of life measurements were significantly improved after the transplant. There was also no significant difference in the quality of life scores between the groups with and without ECMO support.

Kolaitis and colleagues ${ }^{2}$ refer to low quality of life score in ECMO survivors in nontransplant settings as a rationale

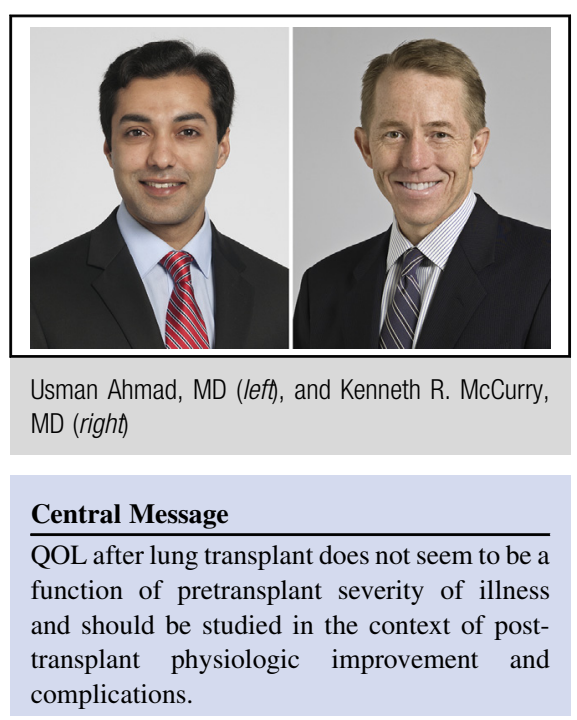

See Article page 440 .

for studying the quality of life in transplant recipients bridged with ECMO. It has to be acknowledged that nontransplant ECMO survivors are usually relatively healthy people who had development of acute-onset respiratory failure requiring mechanical ventilation and ECMO. When these patients recover, they typically are debilitated, are deconditioned, and have much worse pulmonary function than their baseline before the acute illness. It is no surprise that their quality of life is worse after surviving ECMO. Lung transplant, in contrast, is a life-altering and life-improving step for patients with end-stage pulmonary disease, and they come out with pulmonary function much better than their baseline. It is thus not fair to compare transplant and nontransplant ECMO groups.

It should be realized that quality of life scores depend on how the person is feeling at the time of the survey, and not how they were before the intervention. If a patient who is not receiving ECMO support who gets called from home has complications develop after the transplant, their reported quality of life indices will be worse than those of someone who was receiving ECMO support before the transplant but had a smooth posttransplant course. It thus only makes sense that the posttransplant quality of life indices be studied in the context of objective posttransplant measurement of the patient's physiology. I suspect that the immediate posttransplant quality of life indices will correlate closely with postoperative complications, primary graft 
dysfunction, and lengths of intensive care and hospital stays. At the later points (6 months onward), the quality of life indices will likely correlate with functional status and forced expiratory volume.

If we were patients receiving ECMO support being considered for a lung transplant, we would like to know our chances of survival and meaningful quality of life after transplant. Reasonable short- and long-term overall survivals have been well established in patients who undergo ECMO as bridge to transplant. ${ }^{3}$ The slightly lower overall survival in patients receiving ECMO support is likely due to higher rate of posttransplant complications. It would have been interesting to see the effect of pretransplant comorbidities and duration of ECMO support.

On those lines, this study is a remarkable step forward, and we laud the efforts of $t$ Kolaitis and colleagues ${ }^{2}$ in trying to measure quality of life objectively in a complex patient population. We do think that the true impact of pretransplant ECMO on posttransplant QOL should be studied in the context of the posttransplant complications that are likely also responsible for determining overall survival. Questions such as these call for multicenter collaborations, and perhaps transplant programs should consider group research initiatives.

\section{References}

1. Valapour M, Lehr CJ, Skeans MA, Smith JM, Carrico R, Uccellini K, et al OPTN/SRTR 2016 annual data report: lung. Am J Transplant 2018;18 Suppl 1: 363-433.

2. Kolaitis NA, Soon A, Shrestha P, Zhuo H, Neuhaus J, Katz PP, et al. Improvement in patient-reported outcomes after lung transplantation is not impacted by the use of extracorporeal membrane oxygenation as a bridge to transplantation. J Thorac Cardiovasc Surg. 2018;156:440-8.

3. Hoetzenecker K, Donahoe L, Yeung JC, Azad S, Fan E, Ferguson ND, et al. Extracorporeal life support as a bridge to lung transplantation-experience of a highvolume transplant center. J Thorac Cardiovasc Surg. 2018;155:1316-28. 